\title{
GILLES DE RAIZ DE VICENTE HUIDOBRO: EL COMPENDIO DE DEFINICIONES Y LAS HIPÓTESIS ARRIESGADAS
}

Si entendemos que la obra literaria puede quedar planteada como una definición o respuesta a una pregunta, podríamos conjeturar que estas definiciones, preguntas y respuestas tienen que ver muy a menudo - lo que no es, por supuesto, condición necesaria, ni, por añadidura, suficiente - con el fracaso y con la transgresión. ${ }^{1}$

No cabe duda que en la figura de Gilles de Rais encarna la transgresión. Tal vez por ello ha sido tema de obras escritas en diversos momentos. En las líneas que siguen tendré en cuenta, en relación siempre con la pieza teatral de Huidobro titulada Gilles de Raiz ${ }^{2}$, otras dos. Se trata de la novela Allá lejos ${ }^{3}$, escrita por Jois-Karl Huysmans y del ensayo titulado La tragedia de Gilles de Rais ${ }^{4}$, escrito por Georges Bataille. A mi entender y simplificando al máximo, los tres textos, si bien las perspectivas varían, critican una concepción racional y totalizante de la realidad al poner de manifiesto en qué medida sus métodos operan negando lo que no descifran y amputando aquello que amenaza - la amenaza del caos-el orden que se esfuerzan por imponer y declarar natural.

El análisis que me propongo realizar arranca de una constatación inicial: cuando la literatura enraíza en lo histórico, existe el peligroso riesgo de ser tratada como historia, o, si se quiere, como pseudo-historia. La confirmación de los propios esquemas, por parte de la obra, conlleva el rechazo, la valoración negativa, la censura. En este momento, historia y literatura no se distinguen y caemos en el error tradicional que denunció Cervantes. El caballero de la triste figura acaba entonces de resucitar.

Teniendo en cuenta lo afirmado, no se debiera olvidar que el marco histórico es, sin embargo, fundamental. No porque la obra lo considere su referente sino porque esta, aunque ya por su naturaleza lingüística signifique por sí misma, va a significar a partir de él. El juego de la literatura no termina sino que, por el contrario y frente a la historia, empieza en el necesariamente mental marco histórico y puede inaugurar un debate que directa-

1 La propia obra, recordemos, ha sido considerada por diversos autores una transgresión en sí misma (ya en su carácter de no verdad Platón la asocia al mal y acaba por censurarla, los formalistas rusos fundan definiciones generales en torno al hecho literario basándose en este aspecto o, recientemente, Javier del Prado habla del carácter subversivo de la literatura).

2 Vicente Huidobro, Obras completas, Vol. II, Ed. Hugo Montes, Santiago de Chile, Andrés Bello, 1976.

3 Jois-Karl Huysmans, Allá lejos, Barcelona, Bruguera, 1986.

4 Georges Bataille, El verdadero Barba-Azul (La tragedia de Gilles de Rais), Barcelona, Tusquets, 1983. 
mente le afecta. La ficción puede no ser tan inocente, ${ }^{5}$ eso no elimina la posibilidad de que en ocasiones lo sea, como desde determinadas perspectivas se ha querido ver.

Pese a que, en principio, el teatro no se adapte bien a la extensa narración que requiere una biografia ${ }^{6}{ }^{6}$ sorprende lo poco que se sabe sobre Gilles de Rais — suponiendo que la figura histórica es punto de partida para la creación del personaje - leyendo la pieza teatral de Huidobro. Podríamos anticipar que aquí interesan sólo las evocaciones que provoca un nombre y algunos hechos. Es mucho lo que se omite, casi todo lo que únicamente se enuncia. Descendamos a detalles, acompañados de las obras de Huysmans y de Bataille.

El drama de Huidobro permite al lector/espectador construir un "referente ficticio" que va a relacionarse con el "referente histórico" —l del real Gilles de Rais- desde el momento en que: el mismo tiempo y el mismo espacio localizan lo sucedido, a grandes rasgos, concuerdan nombres de personajes y lugares (Gilles de Rais, Morigandais, Blanchet, Juana de Arco, Prelati, castillo de Machecoul, tribunal de justicia de Nantes, etc.) y es parecida la red de atributos básicos que les corresponden junto con las relaciones establecidas entre unos y otros, aunque, lo que me parece fundamental, dicha red de atributos y relaciones resulta en el drama fuertemente distorsionada. Estos puntos en común, en todo caso, no significarían gran cosa de no ir apoyados por los aspectos de contenido argumentales - que paso a exponer:

1) Los dos referentes muestran a una figura, Gilles de Rais, invocando al diablo a medianoche, acompañado de sus criados, en la atmósfera propicia de un bosque próximo a su castillo y, posteriormente, durante el desorden delirante de una orgía.

2) En ambos casos, el personaje pierde de forma progresiva tierras y castillos.

3) La solución a la acuciante necesidad de oro se busca, en ficción y realidad, acudiendo a terceros - Prelati, el mago italiano- versados en alquimia y en prácticas satánicas. Los fracasos se repiten.

4) La violación compartida de la norma constituye práctica repetida, inscrita en el marco de la orgía.

5) La justicia interviene, apresando a Gilles de Rais.

6) El personaje es juzgado y condenado a morir en la hoguera.

Esquematizado de esta forma, se manifiesta que los rasgos comunes construyen el armazón estructural de la obra (sólo nos faltaría un elemento clave, añadido en la ficción: la temática amorosa). Desde esta perspectiva, la estructura parece recoger un movimiento de declive, de caída. Nos describe la multiplicación de la falta y su castigo. Si lo que acabamos de apuntar me parece adecuado referido a la historia, considero que resulta apenas relevante si se aplica a la ficción. Explicar el porqué requiere un nuevo análisis, esta vez centrado en el personaje/eje del texto.

En la obra se busca una definición de Gilles de Rais que terminará siendo un compendio de definiciones. Desde el primer momento los personajes, en sus actitudes, son signi-

5 En realidad, la ficción es siempre lo que colectivamente se decide que es.

6

Llegado el caso, la biografia se resuelve reduciéndola a ciertos episodios más o menos decisivos o incorporando un aparato narrativo que rebasa los límites de la escena. 
ficativos. La premisa estructural se confirma. Un elemento se define por lo que hace ser a otros elementos. En este sentido, observamos al personaje en el espejo múltiple que constituyen los demás. Se manifiesta en los efectos que provoca. Examinemos las primeras páginas: Dos respetuosos siervos tiemblan de miedo en una noche tétrica mientras esperan a Gilles. Este quiere invocar al demonio. A continuación una madre y su hija, de camino hacia el castillo, se ven traspasadas por sentimientos extremos: el horror, la amenaza de la muerte y, por otra parte, la más absoluta fascinación, el deseo devorador e hipnotizante. Una tercera mujer, que viene del castillo, entra en escena. La desesperación de haber sido abandonada por Gilles lleva a la agonía y a la muerte... Súplicas, gritos, actitudes de amor idólatra, odio y terror son constantes repetidas a lo largo de la obra. El origen de lo que se presenta está en Gilles, núcleo en torno al que giran las situaciones incluso estando ausente. Entre lo humano y lo divino, la figura se eleva sobre los demás en tanto que encarna para ellos un ideal ambiguo de muerte y de vida; aquí importa señalar que, como corresponde a todo ideal, no es alcanzable. ${ }^{7}$ Tampoco las interpretaciones, en este sentido, parecen ser tentativas esclarecedoras -estamos en las antípodas de la razón. Esto tendrá sus consecuencias porque el mecanismo motor de diversas escenas y, en buena medida, de la obra, es justamente la búsqueda y hallazgo de explicación, operación que, aunque no se complete, siempre deja tras de sí abundantes aproximaciones, en este caso, no sucesivas pues con frecuencia se repiten, unas no tienen en cuenta otras y carecen, en definitiva, de repercusiones sobre aquello a lo que procuran acercarse. Se pierde así la noción de avance. En lo decisivo, los planteamientos y las respuestas no evolucionan. Repasemos algunas ${ }^{8}$ que he seleccionado:

BLANCHET: .-[...] Gilles de Raiz toma todo demasiado en serio y exagera en todo; va demasiado lejos, no piensa en las consecuencias y no se arredra ante nada. Es insaciable.

MORIGANDAIS: .-[...] Su alma es insaciable y su cuerpo pide siempre. (pág. 582)

LA MADRE: .-Es un monstruo. Debes odiarlo.

LA MUJER: .-Es un monstruo. Lo amo." (pág. 584)

LA MUJER: .-Es más que hermoso, es el sortilegio [...] El es más que hermoso, es triste hasta el horror... ¡ Oh señor Gilles de Raiz! [...] Tú eres la vida y la muerte, el absoluto más allá de lo absoluto; tú eres la angustia de lo inaccesible. (pág. 584)

LA MADRE: .-[...] Es un monstruo que bebe la sangre de las vírgenes y de las adolescentes. (pág. 586)

LA BRUJA: .-Es el Alquimista, es el Astrólogo, es el Encantador, es el Brujo. (pág. 587)

LUCIFER: .-Eres un gran sabio y, además, un artista. (pág. 593)

7 Una bruja, en el primer acto, refiriéndose a Gilles de Rais, exclama: “¡Oh taciturno señor siempre lejano! ¡Para llegar hasta ti, cuántos caminos, cuántos mares hay que atravesar, cuántas montañas, cuántas selvas, cuántas llanuras! Cuántos dragones hay que vencer y embrujos que soportar para en seguida inquirir: “¿Dónde estás?" Porque cuando se llega a ti, tú acabas de partir para otros parajes." (pág. 587).

8 Todas las citas de textos están tomadas de las ediciones que he indicado. Basta, por tanto, con apuntar los números de las páginas. 
LUCIFER: .-Tus riquezas y tu poder son enormes. (pág. 593)

LUCIFER: .-Tú amas el amor más que a nada en el mundo. (pág. 595)

LUCIFER: .-[...] eres la inquietud. (pág. 596)

GILA: .-[...] Tú eres todas las virtudes y todos los vicios. (pág. 608)

GILA: --Tú eres un ser aparte. Hablas como un hombre que fuera otra cosa. (pág. 616)

L'HOSPITAL: .- ¿Entonces, vos sois el amor? El amor negro, el amor bajo... tal vez.

GILLES: .-Yo soy lo que soy.

MALESTROIT: .-Sois el dolor y el crimen. (pág. 631)

MORIGANDAIS: .-[...] es un héroe, su valor y su inteligencia no tienen par. (pág. 635)

JEAN BLOUYN: .-Sois un monstruo de la naturaleza, un caso sin igual de perversión; sois la personificación del mal, un mal sin parecido en la Historia y que sobrepasa todos los límites. (pág. 640)

L'HOSPITAL: .-No sois un hombre, sois una fiera. (pág. 641)

MALESTROIT: .-Sois un blasfemo.” (pág. 641)

HUYSMANS: .-Os digo que era un criminal exquisito, un refinado, un buscador de emociones raras, de placeres fastuosos y horrorosos, un artista supremo y nunca satisfecho. (pág. 644)

ANATOLE FRANCE: .-Es el amor que atrae, tortura y angustia. (pág. 644)

HERNANDEZ: .-[...] sería más bien la muerte que el amor. [...] Lo único cierto es que era un hombre valiente y que fue condenado a muerte contra toda justicia. (pág. 644)

BERNARD SHAW: --No era más que un pequeño pederasta como todo el mundo. (pág. 644)

YO: .-Yo sostengo que era el diablo. (pág. 644)

El ideal permanece idéntico de principio a fin. Los cambios de la realidad no afectan. Por eso no tiene cabida aqui hablar de procesos.

Lo definido, siguiendo con nuestra exposición, se completa con sus propias definiciones:

GILLES: .-[...] amigo Lucifer, en el fondo no soy más que un místico (pág. 595)

GILLES: .-[...] mi maldición es correr siempre tras el gran sueño (pág. 596)

GILLES: .-Yo soy la muerte. (pág. 602)

GILLES: .-[...] Soy libre como los elementos. (pág. 607)

GILLES: .-Yo soy el que debe seguir buscando. (pág. 625)

GILLES: .-[...] Yo soy el vicio, el crimen (pág. 642)

GILLES: .-[...] Soy el diablo. (pág. 642) 
Considerando que toda definición se propone como una fórmula equivalente al término que se define, estas fórmulas resultan tanto más explicativas cuanto más incorporan a ellas mismas el análisis de que son resultado. Partiendo de estos presupuestos, observamos que en una mayoría de las definiciones del texto se procede por medio de sinónimos. De esta forma se evita la explicación, no se nos hace partícipes de un análisis (aunque se suponga que hubo un análisis previo), el objeto se contempla desde la distancia, intocado y posiblemente intocable: algo se identifica con algo. Lo desconocido se asocia a lo conocido y por ello, eliminado su carácter desconcertante, entra directamente entonces en el ámbito de lo familiar, en el ámbito familiar de lo explicado - pero recordemos que no hubo explicación.

Frente a una mayoría, en algunos casos se puede hablar de definición en el sentido tradicional: se señala el género próximo para añadir a continuación la diferencia específica. Así, Gilles de Rais es un hombre que, frente a los demás, es libre o, otro ejemplo, un capitán que se diferencia por ser indomable y místico... El procedimiento es de tipo retórico. Se opera mediante reducciones totalizantes y ampliaciones particularizantes, es decir, proponiendo sinécdoques. Lo desconocido es previsto en estos esquemas de manera muy limitada como mera combinación desconocida de lo conocido.

Hay dos hechos inquietantes: a menudo sucede que lo desconocido se asocia a lo que se desconoce. Nada, por tanto, se determina. Por otra parte, la multiplicidad de las definiciones conlleva una anulación. Unas niegan a otras. No hay acuerdo. La múltiple definición termina en indefinición. El enigma se redondea englobando enigmas, armonizando contrarios; enigma ya por excelencia.

Enlazando con lo anterior, el propio Gilles de Rais declara sus inquietudes y metas, lo que pudiera cubrir el hueco explicativo que se acusa en las definiciones y constituir, indirectamente, una nueva definición; veamos: en el pacto con Lucifer, hay una solicitud "El amor más grande, la mayor ciencia, el poder más grande" (pág. 592) a cambio del alma. El buscador de absolutos sale a superficie; sobre todo, cuando se nos menciona acto seguido, que ya es el más amado de los hombres, un gran sabio y un artista al que respaldan riqueza y poder enormes. El absoluto a perseguir es acorde a un impulso excesivo, sobrehumano. En esta constante búsqueda de trascender a través de los actos a un más allá definitivo, se revela un impulso metafísico y místico. La conversación con Lucifer ilustra lo que afirmo: habla Gilles:

"Conozco el amor, conozco el cuerpo del amor [...] pero eso no es todo. Hay algo, sabes tú, algo que se me escapa. Hay algo que permanece detrás del amor, algo que se presiente... ¡Qué angustia! Algo que no se puede alcanzar y que es más grande que el amor."

En otro lugar, una mujer describe una jornada amorosa en estos términos:

"como un guerrero infatigable, quebraba mi cuerpo como a las torres de una ciudadela... Luego, aturdida, muda, yo lloraba, lloraba, y me revolcaba entre un paraíso y un infierno, un infierno quizá más deseable que el mismo paraíso. El, inmóvil, respiraba horriblemente como un dragón, y 
decía con voz sorda: "Esto no es, todavía no es... Hay algo más, tú no eres. El misterio sagrado se oculta." (pág. 586)

Una vez tras otra, la misma idea se expone: "Quiero lo que siento ahí, casi al alcance de mis manos y que se burla de mí en la sombra..." (pág. 619). Estas repeticiones van creando una atmósfera de inmovilidad y extatismo en el texto. No se producen transformaciones esenciales en los puntos de vista y en el significado del personaje, lo que contrasta con las cambiantes circunstancias que lo amenazan y con los diferentes estados por los que atraviesa.

La búsqueda se agota en un recorrido limitado. Gilles de Rais golpea una y otra vez los límites de los actos, presintiendo una dimensión oculta e inaccesible. Choca contra los límites de la existencia, ansiando, insatisfecho, constatando la insuficiencia del acto prohibido: "Raza maldita, no habéis inventado nada para mí, nada, ni aun el crimen. Voy a destrozarme para salir de mi cuerpo." (pág. 618).

La búsqueda es dramática. El fin justifica aquí cualquier medio: la pérdida del alma, los crímenes... El propio interés desbarata toda convención. El canto soberano y transgresor de libertad ilimitada valida y posibilita la búsqueda ilimitada:

"mi rey ahora soy yo. [...] Desafío y provoco. No defiendo la libertad de un país; defiendo mi propia libertad. Todo lo que huele a imposición me rebela. Basta que la ley se oponga para que me subleve. Basta que la moral diga que no, para que yo diga que sí." (pág. 606)

Leve ejemplificación de lo definido, los actos, las actitudes, subrayan aspectos expuestos y añaden nuevos matices. ¿Cómo se manifiesta lo ideal en los actos? Repasemos algunos datos. Lo ideal es la oposición a lo no ideal. El acto ideal se opone al no ideal. Se trata aquí de una diferencia cuantitativa pero también cualitativa. Gilles de Rais contradice en sus actos a los de una colectividad: el héroe se cubre de cualidades únicas y realiza la acción excepcional, el amante que fascina no halla sustituto posible, al político le corresponde maquinar en solitario el plan definitivo y sorprendente, el criminal palpa el límite de lo prohibido permitiéndose afirmar que "no hay nadie en la tierra que haya hecho lo que yo he hecho, que se atreva a hacer lo que yo hago" (pág. 619) y el buscador comienza por sentarse junto al propio demonio para proponerle un acuerdo.

Se observa además, añadiendo a lo anterior, que cada situación es marco de una conversación. Se trata de situaciones básicamente extáticas: en ellas, se despliega el juego de un debate, dinámica — casi siempre - de la escena. Gilles de Rais, sobre todo, habla. El acto es la palabra y la palabra rechaza, revela un nuevo punto de vista oscuro e incontestable al mismo tiempo. En consonancia, aclarar lo propio y corregir - negar- lo ajeno son dos constantes. De nuevo, la distancia se subraya.

Por otra parte, la soberanía del ideal es indiferente a lo que no es ella misma. La indiferencia hacia lo otro es rasgo característico que los actos revelan. La no indiferencia es el reconocimiento de una igualdad constitutiva. El ideal, por representar una radical diferencia básica, es indiferente. Brilla, horrible y magnifico, en solitario. Paso a ilustrar lo dicho 
con algunos ejemplos: Prepárandose a invocar al diablo, Gilles besa a una mujer muerta. Exclama: "Cómo queman sus labios... Besa mejor muerta que en vida." (pág. 589).

Los instrumentos necesarios para la invocación satánica: un pedazo de piel y unos clavos, reciben los siguientes comentarios: "Dulce al tacto la piel de muchacho" y "He necesitado veinte días para hallar estos clavos de ataúd de supliciado: castigan poco en esta región" (pág. 590).

El desdén hacia el sufrimiento de las mujeres que lo aman y, en general, hacia el dolor producido, son atributos de quien no pertenece a la esfera común de lo social. No me parece apropiado hablar de insensibilidad -concepto que opera desde lo colectivo y sobre lo colectivo- pues tendría el mismo sentido que asegurar la insensibilidad del caníbal o de un tigre. En esta línea, el acto por excelencia del ideal negativo es el crimen - el crimen ligado a la búsqueda es sacrificio- y la actitud que le corresponde es la ausencia de remordimientos. Así se expresa Gilles de Rais: "No tengo remordimientos de conciencia. Eso lo dejo a los imbéciles" (pág. 619) y así describe algunas carnicerías:

"Os he destrozado, os he torturado y he asido todo el goce que podía haber en vuestros cuerpos miserables, pero no había nada." (pág. 620)

"Reventé tu cabeza y tu cerebro voló al cielo como pétalos perfumados de sueños. Hundí mis manos en tus entrañas, mordí tu corazón palpitante como un pescado y nada, nada..." (pág. 620)

Los demás son sometidos, en un acto de naturalidad, a un interés soberano que, afirmándose frente a ellos, termina por negarlos. Afirmación y negación que identifican, elevando y aislando.

Es momento de relacionar lo que vamos exponiendo con los textos de Huysmans y de Bataille. A modo de introducción, vale la pena recordar que en Allá lejos, la historia de Gilles de Rais es la historia dentro de la novela, escrita por uno de los personajes. Esto crea un espacio abierto al metadiscurso que no deja de aprovecharse. Leemos algunas reflexiones del protagonista escritor "Durtal" que originan su obra:

"el naturalismo, confinado en monótonos estudios de seres mediocres y evolucionando entre interminables inventarios de salones y campiñas, conducía en línea recta a la esterilidad más completa cuando se es honrado o clarividente, y en el caso contrario, a las más fatigosas repeticiones [...] Es necesario - se decía - conservar la veracidad del documento, la precisión del detalle, el lenguaje fastuoso y nervioso del realismo; pero también es necesario hacerse buzo de almas y no pretender explicar el misterio por las enfermedades de los sentidos." (páginas 14, 15).

A esto hay que sumar la siguiente convicción: "no hay dicha sino en uno mismo y por encima del tiempo [...] Barba Azul me interesa más que el tendero de comestibles de la esquina" (pág. 26). La necesaria huida hacia el pasado y la búsqueda de una alternativa al agotado naturalismo son, resumiendo, los móviles esenciales. Para terminar, las perspectivas del proyecto se aclaran en este fragmento: 
"Dadas sus ideas respecto a la historia, no se consideraba más capacitado que otro para pintar un Barba Azul exacto; pero por lo menos tenía la certeza de no desnaturalizarlo, [...] de no hacer de él esa mediocridad, en lo bueno o en lo malo, que agrada a las muchedumbres. Para tomar impulso poseía, a guisa de trampolín, una copia de la Memoria que dirigieron al rey los herederos de Gilles de Rais; las notas que él mismo había tomado sobre el proceso criminal de Nantes, del cual varios autos están en Paris; extractos de la historia de Carlos VII, de Vallet de Viriville; y por último, la noticia de Armand Gueraut y la biografía del abate Bossard. Y esto le bastaba para poner erguida la formidable figura de aquel satánico, que fue, en el siglo XV, el más artista y el más exquisito, el más cruel y el más malvado de los hombres." (pág. 34).

En el caso de Bataille, el tema de Gilles de Rais, se justifica en la medida en que viene a ejemplificar algunos aspectos de las teorías que el autor sostiene acerca de la naturaleza humana. De Rais encarna el hombre en su estado soberano. Explicar lo que lo ha hecho posible son metas centrales de la obra. La época, circunstancias familiares y peculiaridades personales se rastrean con esta finalidad.

Tanto Huysmans como Bataille describen, refieren motivos y actos. Por el contrario, en la obra de Huidobro, no se intenta exponer ni analizar. Se prueba o más bien se parte de que lo indescifrable es indescifrable y se explica por lo indescifrable. Queda abierto a la sugerencia, a la sugerencia de la hipótesis. ¿Quién era Gilles de Rais? ¿"El amor"? ¿"La muerte?" ¿"El propio diablo"? En este planteamiento, indicios de humanidad, gestos que amenazan ese ente ideal y misterioso, se eliminan: Así el carácter infantil e incapaz de cálculo, así la ingenuidad y credulidad tontorrona de Gilles, el terror al diablo, las toscas argucias de criados interesados en aprovecharse de él, la poca visión política, las lágrimas ante los jueces, la falta de astucia en la defensa, las peticiones de perdón, el arrepentimiento, la confesión, el entierro. En combinación con lo anterior, cuanto puede enriquecer lo enigmático, redondear el enigma de la figura excesiva, se añade: la extremada inteligencia, el conocimiento de lo oculto, el poder de inexplicable atracción, la búsqueda de un misterio imposible, el ansia todavía de un grado de perfección sobrehumano... El resultado obtenido por Huidobro es una figura que difiere, lo que no tendría ninguna importancia en una obra de teatro, si esto no conllevase otras consecuencias.

Nuestras afirmaciones deben engarzar ahora en un contexto. La literatura de fondo histórico crea un referente literario que en mayor o menor grado se asemeja al referente de la historia. No hay identificación pero uno se mira en el otro. Lo que varía adquiere significado y suscita preguntas. La literatura no necesita responder, avalada por la ficción. Pero la historia debe intentar hacerlo. Debe justificar sus cambios respecto al referente literario. Si es incapaz de esto, la insuficiencia de sus procesos se revela. Creo que es adecuado leer Gilles de Raiz bajo este punto de vista. De esta forma, la obra se muestra orientada hacia la propuesta de lo que llamo "hipótesis arriesgadas", esto es, una suma de añadidos hipotéticos, sorprendentes e improbables por contradecir afirmaciones históricas y que la propia historia tal vez no es capaz de refutar más que arguyendo la misma falta de pruebas que, sin embargo, funda, paradógicamente, parte de sus declaraciones. La 
figura completa de Gilles de Rais constituye una hipótesis arriesgada. Hay un detalle de especial interés: su actitud desdeñosa y altanera durante el juicio desmiente la versión histórica, pero esto recibe explicación: los documentos están falseados porque se ajustan a intenciones parciales. Argumenta Gilles:

"Sé que mañana diréis que he confesado mis faltas y que estoy arrepentido. Diréis que pedí perdón, me calumniaréis ante la Historia para que mi arrepentimiento sirva de ejemplo. ¡Ah! ¡Miserables! Vuestra audacia llegará hasta pintar a Gilles de Rais como un muchacho adolorido.” (pág. 641).

Volvemos a nuestro texto, a fin de localizar otras hipótesis arriesgadas. No tardamos en encontrarlas: Juana de Arco es creación de Gilles de Rais; responde a una estratagema política ideada por él. De igual modo, Juana no muere en la hoguera porque es sustituida por otra. Ella escapa. Este hecho recibe algunos comentarios: se consigna que "puede crear un equívoco en la Historia" (pág. 609) y "que sobre la tierra ocurren cosas muy extraordinarias" (pág. 613). En estas circunstancias, la pregunta no se hace esperar: "Decidme, vosotros, ¿creéis que en el mundo se haya sabido la verdad alguna vez de cualquier hecho?" (pág. 613).

Algunas creencias reciben nueva versión por el mismo procedimiento: es el caso de la victoria de Dios sobre Lucifer, gracias a un error, de la relatividad del bien y del mal -la no negatividad de ninguna de las dos, sus idénticas implicaciones o de un Don Juan que detesta a las mujeres por impedirle llegar a ser cura, su auténtica vocación.

Retornando al principio, si toda obra define, el drama de Huidobro define multiplicando enigmas. Los resultados contradicen lo admitido. $\mathrm{El}$ conocimiento objetivo es, pues, centro de discusión. En este sentido, ya la propia naturaleza del lenguaje, instrumento básico, proporciona un punto de apoyo dudoso, fomenta el desconcierto: "Detrás de cada palabra hay un laberinto que recorrer. Cada frase es un río bajo la arena." (pág. 607). ${ }^{9}$ El gesto de certeza no llega a anular un gesto de duda. El conocimiento deja su lugar a las hipótesis y estas aquí, en consonancia con lo que sobre ellas se afirma en el cuento La muerte y la brújula de Borges, cumplen, frente a la realidad, con el único requisito de ser interesantes.

Todo lo que venimos señalando se engloba en una última hipótesis sobre la realidad. Lo natural y lo sobrenatural se superponen. La realidad es el misterio, como el texto no cesa de repetir. La simpleza del pensamiento se enriquece con la multiplicidad de aspectos que convergen en él. Desde la abundancia de fenómenos físicos apenas perceptibles -roces, murmullos, sonidos desconocidos, presencias imprecisas, signos vagamente interpretados o malinterpretados - los personajes tropiezan con una opacidad básica. Cito algunos ejemplos:

9 La propia obra se vale de las posibilidades del lenguaje y en concreto de la imagen poética para crear, en consecuencia con planteamientos creacionistas, una realidad nueva, desconocida e inquietante. 
BLANCHET (Mirando al aire, atento el oído):

-¿Qué es eso? Algo acaba de rozarme en la noche.

MORIGANDAIS: .-Tu propio terror.

BLANCHET: .-No. Hay algo que se abre paso en el aire.

MORIGANDAIS: .-Es tal vez un adiós que se evade a través del vacío. (pág. 582)

LA MADRE: .-Hija mía, algo que en el aire flota me advierte que debemos huir.

LA HIJA: .-Madre, algo que en el aire flota me advierte que debemos continuar.

(pág. 583)

GILLES: .-¿Quién va? Prelati, ¿quién se acerca? Mira, mira...

PRELATI: .-No viene nadie, señor, son delirios de vuestra imaginación... (pág. 619)

A la diferencia de los sentidos se añade cierta capacidad de engaño o autoengaño. En definitiva, se ve "realmente" lo que se quiere ver. La realidad se cubre - esconde- bajo el velo de la creencia, de la leyenda. Gracias a ello, Gilles de Rais vuela sobre su castillo:

LAS DOS ALDEANAS: .¡¡Oh, sí! ¡Qué lejos vuela!...

MORIGANDAIS: .- [...] mientes. Cállate o por San...

ALDEANO: .-Pero, señor, estoy viéndolo.

MORIGANDAIS: .-Mientes. No ves absolutamente nada.

GILLES: .- [...] Cálmate, Morigandais, déjalos hablar. Para la leyenda eso es bueno. (pág. 604)

La interpretabilidad de lo real se enreda en el conocido juego de la apariencia y la esencia. Cervantes, Quevedo o Galdós dieron una dimensión social a lo que tiene ahora resonancias metafísicas. La esencia desaparece en la apariencia y esta última no se identifica con lo contingente sino con lo postizo. La verdad, por tanto, no es real. Si ficción e historia comparten la característica de la irrealidad - lo que, ha llevado a suponerlas igualmente ficticias - se diferencian, sin embargo, por la actitud con que se reciben. Dos lecturas de un mismo texto, definen el texto de forma diferente. La realidad no puede dar validez a ninguna. La Biblia, recordando a Borges, es literatura fantástica $\mathrm{y}$, al tiempo, deja de serlo en cuanto una colectividad cree en ella.

Dentro del juego entre apariencia y esencia, se explica la paradoja constante. El esquema de la causa y el efecto funciona de forma sorprendente e impredecible debido a una malinterpretación inicial. La lógica, sin embargo, está presente y justifica una imagen de mundo al revés. Jugando con meras palabras, es la lógica de lo ilógico. Los ejemplos son abundantes. Elijo algunos: el amor identifica placer y dolor (vida y muerte), el mujeriego Don Juan no entiende una palabra de amor o mujeres y vence en sus duelos por no saber manejar la espada, Lucifer causa risa, Dios gana su batalla gracias a una equivocación. La ausencia de Gilles, el criminal, causa la muerte, Dios es asesinado por error, a manos de un devoto suyo, "Cuando se tiene la verdad del lado de uno es imposible defenderse bien" (pág. 612), "Todo pueblo siente vivir más a sus muertos que a sus vivos" (pág. 613), "los oídos no oyen lo que dice todo el mundo" (pág. 614)... Para terminar, copio un razonamiento. Dice Gilles: 
"Un hombre no es nunca lo que representa. Un hombre hace siempre lo que no es en realidad, busca lo que no posee. Un verdadero músico no compone música. Es demasiado fácil para él. Lo que atrae es lo maravilloso, lo que está lleno de misterio para nosotros. [...] En la vida se juega siempre a ser lo que no se es" y un poco más adelante, concluye: "Sólo las tonterías no contienen contradicciones." (pág. 649)

En consecuencia, los personajes manifiestan una identidad que nadie les reconoce.

Con estas úlimas hipótesis arriesgadas, se acaba de articular una realidad -referente literario- que contemplándose en la realidad histórica se descubre inquietantemente transgresora. Lejos del horror físico que la figura monstruosa de Gilles de Rais debiera provocar, el texto se complace entonces, por las características del hecho amenazador que hemos ido exponiendo, en pulsar un terror fundamentalmente intelectual.

Resultaría relativamente sencillo, incluso para un individuo de escasa imaginación, relacionar el personaje de Gilles con el propio Vicente Huidobro: ególatra, polémico, "antipoeta y mago", según se define en Altazor (canto IV, 282). En concreto, el episodio folletinesco y escandaloso que constituyó el encuentro fulminante con la menor de edad Ximena Amunátegui - para colmo, hija de un poderoso hombre público- y su posterior rapto, recuerda a algunos pasajes del drama. Sin embargo, descarto este tipo de sugerencias porque, según creo, se fundan en unas premisas bastante cuestionables en torno a la literatura: respondiendo a un modo puramente romántico de concebir el hecho literario, la obra se concibe como la expresión de un sujeto de la enunciación que coincide con el autor. En caso extremo, la obra se explica por la vida y desde la obra se accede a la vida.

En su lugar, me parece de mayor interés, a raíz de nuestro análisis, situar Gilles de Raiz, publicado por primera vez en París, en el año 1932, en la corriente crítica y escéptica iniciada a finales del siglo XIX en respuesta al entusiasmo y la confianza que habían despertado los métodos científicos. En esta línea coincide con el teatro de vanguardia en general al insistir en romper la visión naturalista: renovación del lenguaje -recurriendo, en este caso, a imágenes creacionistas-, incorporación de nuevas técnicas - aquí cinematográficas-, puesta en escena de obsesiones y fantasías, descubrimiento de una dimensión psicológica y secreta no analizable en términos de una casuística y, en definitiva, rechazo de explicaciones enraizadas en el determinismo.

Al destacar lo oscuro e irracional en lo humano, el perfil delirante y onírico, parece oportuno hablar de una conexión con propuestas surrealistas. Basta con observar la afinidad entre objetivos de este movimiento: "el surrealismo apunta hacia la utopía de la transformación del hombre a través de la liberación de las fuerzas del inconsiente"10 y la actitud de un personaje que no duda en exclamar: "quiero soltar las fieras de mi alma... ¡Corred por las llanuras, oh mis leopardos!” (pág. 621).

Si hoy día, más allá de aquellos nuevos tiempos, conocedores del antes y del después, no nos causa sorpresa el principio demoledor que impulsa este drama, es quizá debido a

10 Jorge Schwartz, Las vanguardias latinoamericanas. Madrid, Cátedra, 1991, pág. 34. 
que ese mismo principio ha alimentado algunas de las aportaciones más enriquecedoras de este agonizante siglo XX.

Povzetek

\section{"GILLES DE RAIZ" VICENTEJA HUIDOBRA: SKUPEK DEFINICIJ IN TVEGANE HIPOTEZE}

Avtor v svojem članku analizira gledališko delo Vicenteja Huidobra Gilles de Raiz, ki je izšlo leta 1932 v Parizu, in ga primerja z romanom Joisa-Karla Huysmansa Nekje daleč (Allá lejos), esejem Georgesa Batailla Tragedija Gillesa de Raisa (La tragedia de Gilles de Rais) ter zgodovinskimi dogodki, ki so osnova oziroma navdih vsem trem delom. Medtem ko se pri Huysmansu zgodba o Gillesu de Raisu morilcu, astrologu, magu in mistiku - pojavlja kot zgodba v zgodbi, Bataillu služi za analizo človeške narave. Tako Huysmans kot Bataille analizirata dogodke ter razlagata motive in dejanja te kontradiktorne literame in zgodovinske osebnosti 15. stol. Prav nasprotno pa Huidobro, kot ugotavlja avtor članka, opise svojega junaka zreducira na minimum, s čimer ustvari odprto, vsakršni razlagi izmikajoče se in v svoji zgradbi popolnoma moderno gledališko delo, s katerim postavlja pod vprašaj verodostojnost zgodovine, ki jo nazadnje poistoveti s fikcijo. 